\title{
Double-guidewire technique facilitates endoscopic ultrasound-guided biliary drainage for hilar biliary obstruction
}

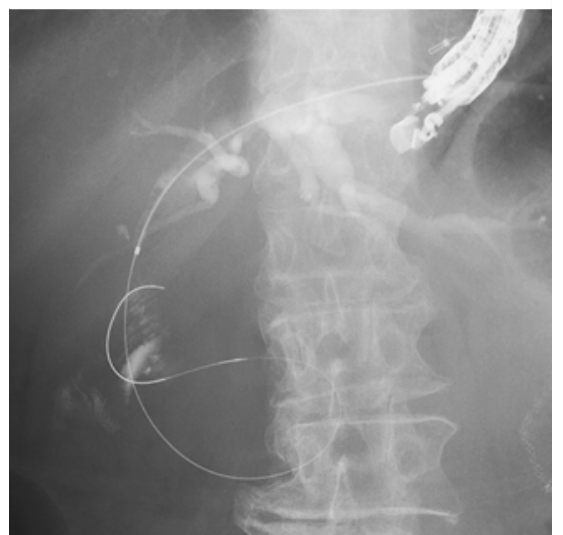

- Fig. 1 A standard guidewire was advanced into the afferent limb without insertion into the right hepatic duct.

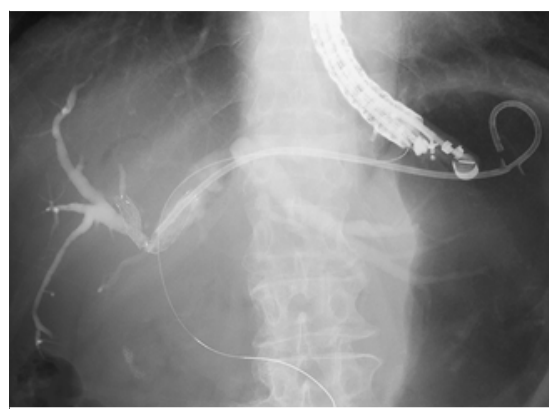

- Fig. 3 An uncovered metal stent was used to bridge the right and left hepatic ducts beyond the hilar biliary stenosis, and a plastic stent was then deployed from the left hepatic duct to the stomach.

A 74-year-old woman with a 2-year history of pancreaticoduodenectomy for pancreatic cancer was admitted to our hospital for treatment of obstructive jaundice due to a recurrent tumor, which divided the right and left hepatic ducts (RHD and LHD, respectively). Endoscopic ultrasound-guided biliary drainage (EUSBD) was planned.

A curved linear EUS device was inserted into the stomach. Segment 2 of the dilated intrahepatic bile duct was punctured with a 19-gauge needle. A 0.025-inch guidewire (VisiGlide 2; Olympus, Tokyo, Japan) was then easily inserted into the
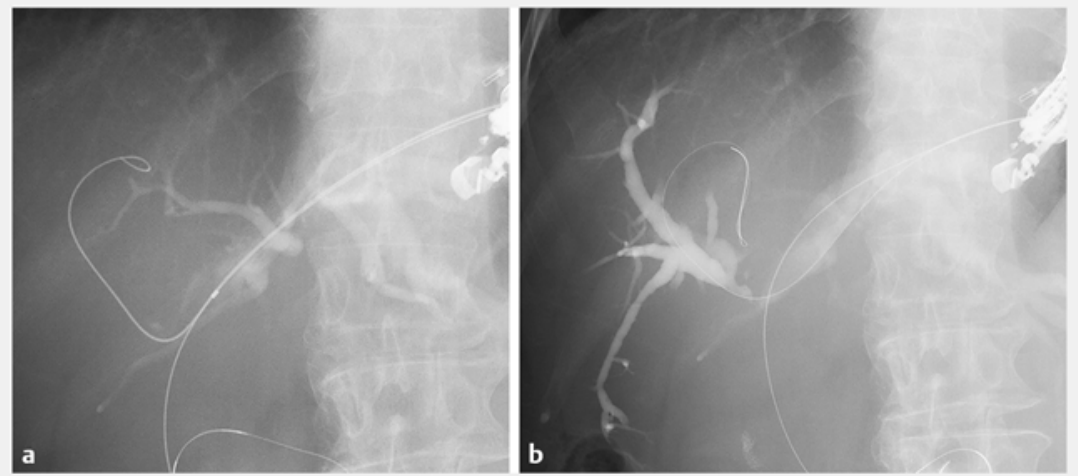

- Fig. 2 Access to the right hepatic duct. a A hydrophilic guidewire was inserted into the right hepatic duct via the other lumen of a double-lumen catheter. $\mathbf{b}$ Cholangiogram of the right biliary system was obtained after insertion of an endoscopic retrograde cholangiopancreatography catheter.

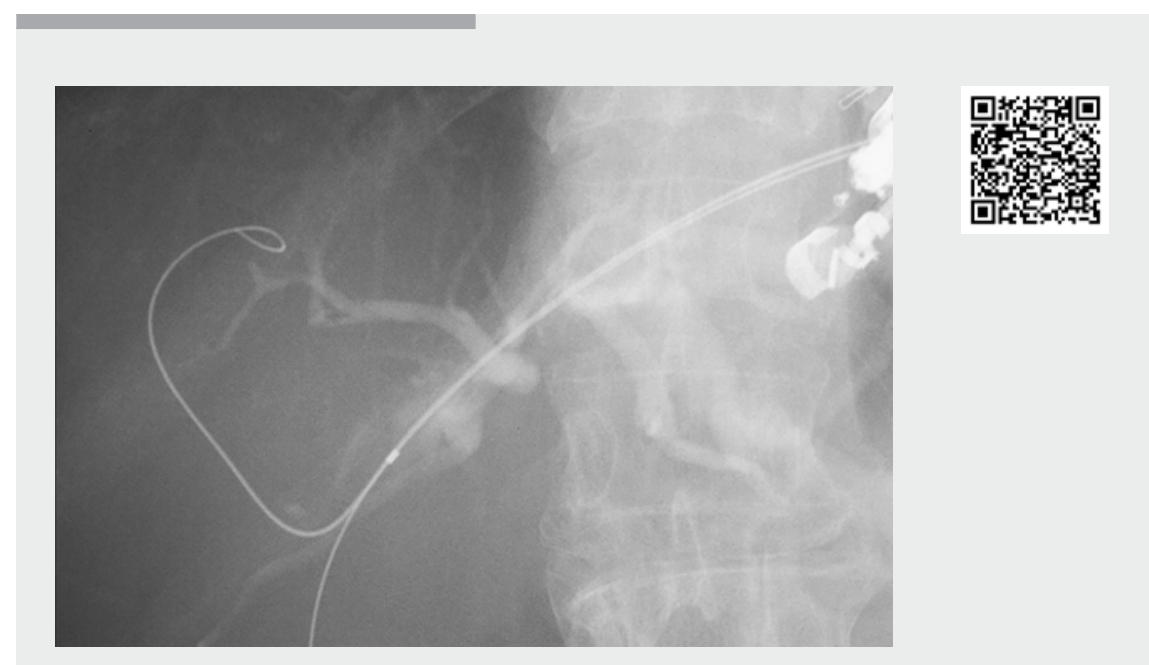

Video 1 Guidewire insertion into the right hepatic duct from the left hepatic duct beyond the obstruction was impossible during endoscopic ultrasound-guided biliary drainage. However, this was feasible with a double-guidewire technique.

LHD and the afferent limb. Subsequently, we inserted a single-lumen catheter along with the guidewire into the LHD; however, the guidewire could not be introduced into the RHD ( $\triangleright$ Fig.1, - Video 1). Therefore, we changed the catheter to a double-lumen cannula (Uneven double-lumen cannula [short type]; Piolax Medical Devices, Kanagawa,
Japan) and inserted a 0.025-inch hydrophilic guidewire (Radifocus; Terumo, Tokyo, Japan) into the LHD via the other lumen. The second guidewire could be manipulated to reach the RHD ( $\triangleright$ Fig. 2). Subsequently, an uncovered metal stent (Bile Rush; Piolax Medical Devices) was placed to bridge the obstruction of the RHD and LHD. Finally, a 7-Fr plastic stent 
was inserted from the LHD to the stomach ( $\triangleright$ Fig. 3). No adverse event was encountered and the jaundice resolved.

EUS-BD using a single-lumen catheter is widespread; however, EUS-BD for hilar biliary obstruction is quite uncommon because guidewire manipulation is required to bridge the left and right biliary systems beyond the obstruction [1,2]. A double-guidewire technique using a double-lumen catheter can facilitate the procedure. The technique includes two rationales: first, the first guidewire prevents entry into the untargeted duct, and the second guidewire can be advanced towards the targeted duct. Second, the first guidewire serves as a landmark for the manipulation of the second guidewire.

Endoscopy_UCTN_Code_TTT_1AS_2AD

Competing interests

None
The authors

Hirotoshi Ishiwatari ${ }^{1}$, Tatsunori Satoh ${ }^{1}$, Junya

Sato ${ }^{1}$, Junichi Kaneko', Hiroyuki

Matsubayashi $^{1,2}$, Hiroyuki Ono ${ }^{1}$

1 Division of Endoscopy, Shizuoka Cancer Center, Shizuoka, Japan

2 Division of Genetic Medicine Promotion Shizuoka Cancer Center, Shizuoka, Japan

Corresponding author

\section{Hirotoshi Ishiwatari, MD, PhD}

Division of Endoscopy, Shizuoka Cancer Center, 1007 Shimonagakubo Nagaizumicho, Sunto-gun, Shizuoka, Japan

Fax: +81-55-9895551

ishihiro481019@gmail.com

\section{References}

[1] Ogura T, Sano T, Onda S et al. Endoscopic ultrasound-guided biliary drainage for right hepatic bile duct obstruction: novel technical tips. Endoscopy 2015; 47: $72-75$

[2] Minaga K, Takenaka M, Kitano M et al. Rescue EUS-guided intrahepatic biliary drainage for malignant hilar biliary stricture after failed transpapillary re-intervention. Surg Endosc 2017; 31: $4764-4772$
Bibliography

DOI https://doi.org/10.1055/a-0915-1917

Published online: 4.6.2019

Endoscopy 2019; 51: E321-E322

(c) Georg Thieme Verlag KG

Stuttgart · New York

ISSN 0013-726X

\section{ENDOSCOPY E-VIDEOS}

https://eref.thieme.de/e-videos

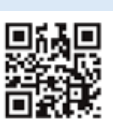

Endoscopy E-Videos is a free access online section, reporting on interesting cases and new

techniques in gastroenterological endoscopy. All papers include a high quality video and all contributions are freely accessible online.

This section has its own submission website at https://mc.manuscriptcentral.com/e-videos 